\title{
O Estatuto do Nascituro: quando os documentos legislativos constroem pessoas ${ }^{1}$
}

\author{
Bruna Potechi \\ Universidade Federal de São Carlos, São Carlos, São Paulo, Brasil
}

DOI: $10.11606 /$ issn.2316-9133.v22i22p315-325

resumo Este artigo visa demonstrar algumas maneiras de os documentos legislativos construírem pessoas. Partindo do Estatuto do Nascituro, projeto de lei que tramita na Câmara dos Deputados e que defende embriōes, fetos, ou nascituro - como pretende conceituar os seres concebidos, mas ainda não nascidos - como uma pessoa, pretendo expor como os documentos que dialogam com este projeto de lei articulam seus diferentes argumentos de forma a construir diferentes pessoas. Assim, entraremos no conjunto de documentos - leis, projetos de lei, pareceres, votos em separado, justificativas de projetos de lei, etc. - que dispóe sobre aborto e novas tecnologias, dois momentos onde o nascituro pode aparecer como uma pessoa, ou não-pessoa. E ainda verificar como são atribuídos diferentes níveis de pessoalidade. palavras-chave Pessoa; Documentos; Legislação; Novas tecnologias reprodutivas; Aborto

The "Unborn Statute": when legislatives documents are used to construct persons

abstract This article aims to demonstrate some of the ways legislative documents are used to construct persons. Starting from the Unborn Statute, a bill a law that is running in the Brazilian House of Representatives and that defends embryos, fetuses or the unborn - as it is intended to describe beings that have been conceived, but not yet born - as a person, with the intention of exposing how documents that dialog with this bill articulate its different ar- guments so to construct different persons. That way, we will approach the body of documents - laws, bills, reports, separate votes, bill justifications etc. that talk about abortion and new technologies, two moments where the unborn may appear as a person or non-person. Also, verify how different levels of personality are attributed.

keywords Person; Documents; Legislation; New reproductive technologies; Abortion.

Este artigo se constrói a partir de um Projeto de Lei, que fora aprovado em 2010, pela Comissão de Seguridade Social e Família, o PL 478 de 2007, conhecido como Estatuto do Nascituro. ${ }^{2}$ O Estatuto do Nascituro se apresenta como um projeto de lei prevendo assegurar que embriōes, fetos, zigotos, ou, todos os seres concebidos, mas ainda não nascidos chamados na proposta legislativa de nascituros - são pessoas. São assim, pessoas legais, e devem ter seus direitos conferidos às Pessoas (no sentido aqui da Pessoa Física da Constituição Federal), consideradas, enquanto tal, nesse cenário. São inseridos no PL direitos à imagem, honra, integridade física, vida, herança, convívio familiar, entre outros. Assim, desde o momento da concepção, o nascituro é protegido por vias legais; ele é uma pessoa e deve ser encarado enquanto tal - mesmo que in vitro. O Estatuto proibiria, portanto, casos de aborto (mesmo os atualmente previstos em lei) e pesquisa ou descarte de embrióes in vitro. 
Pretendo esboçar nesse texto como os documentos legislativos - as leis, códigos, normas, projetos de lei, pareceres, votos em separado e justificativas de propostas de leis - que dialogam com o Estatuto do Nascituro, podem tornar um mesmo momento do desenvolvimento humano pessoa, ou melhor, tornar ou não tornar este momento uma pessoa. Ou ainda, atribuir diferentes níveis de pessoalidade aos personagens construídos por estes documentos.

A questão inicial é como poderia o Estatuto do Nascituro ser um projeto de lei que, ao defender o nascituro enquanto uma pessoa, propóe modificar leis em vigor sobre aborto e novas tecnologias reprodutivas, ou ainda como diferentes propostas de lei poderiam ser apresentadas ao legislativo promovendo diferentes formas de construção do nascituro enquanto uma pessoa. Por fim, seria o nascituro uma pessoa legal?

A pessoa que pretendo esboçar nesse espaço não remete ao conceito de pessoa em Antropologia apresentado por Mauss, ${ }^{3}$ ou ainda, a ideia de indivíduo presente nas sociedades ditas "ocidentais". ${ }^{4}$ A pessoa aqui apresentada remete a um possível recorte de uma condição ou categoria da Pessoa Física, que apresentado como recorte é legitimado enquanto uma pessoa no acervo documental analisado. ${ }^{5}$ Isto é o que considero ser uma pessoa legal.

O recorte do meu campo passa, então, para esse material que foi apresentado ao legislativo brasileiro, mais especificamente à Câmara dos Deputados por onde o Estatuto do Nascituro tramitava. Quais outros projetos de lei tentavam regular o nascituro, ou melhor, esse momento do desenvolvimento humano? Cheguei assim, aos dois temas que o próprio Estatuto do Nascituro propunha regular - os temas de aborto e novas tecnologias reprodutivas. ${ }^{6}$ Assim, pude verificar quais eram as diferentes propostas a regular aborto, e as novas formas de reprodução humana - duas áreas em que o mo- mento anterior ao nascimento humano estava presente, mesmo que de forma indireta.

Pude notar, então, que dentre os documentos que regulavam aborto e novas tecnologias reprodutivas e os projetos de lei que eram apresentados sobre ambos os temas, não existia um consenso sobre a pessoa do nascituro. Não poderíamos estipular se a Constituição Federal, o Código Civil, o Código Penal, ou o Estatuto da Criança e Adolescente criavam alguma rigidez sobre esse ser pessoa - vimos que, pelo contrário, estas leis e demais pactos assinados pelo Brasil, proporcionavam diferentes leituras e interpretaçôes, de forma a validar justificativas de ser pessoa do nascituro, ou náo ser (o que veremos mais adiante), pautadas nesses documentos em vigor.

Além disso, pude perceber que mesmo que os documentos apresentados à Câmara dos Deputados sobre aborto e novas tecnologias reprodutivas dispusessem sobre um objeto comum - o que podemos agora chamar de nascituro - esses dois temas não pareciam ter um mesmo objeto, pelo contrário, pareciam promover um distanciamento entre seus argumentos. De um lado, os projetos de lei sobre aborto tinham como comum diálogo uma discussão sobre as pessoas que apareciam em tais documentos, enquanto os projetos de lei sobre novas tecnologias tinham como principal argumentação a defesa pela possibilidade da família surgir com o acesso às novas tecnologias reprodutivas. Ou seja, de um lado pessoa, de outro, família. Quero neste pequeno espaço demonstrar como, de forma resumida, os documentos analisados podem e articulam suas justificativas de forma a produzir diferentes pessoas.

Delimitar o campo etnográfico me levou a definir os documentos como um campo de pesquisa, ou melhor, os documentos como materiais e objeto de pesquisa. Os documentos não são apenas o meio pelo qual a pesquisa se realiza, mas instrumento e objeto de pesquisa, 
O Estatuto do Nascituro: QUANDo os Documentos LegisLativos CONSTROEM PESSOAS $\mid$ 3I7

constituindo nossa "aldeia-arquivo" (FERREIRA, 2009). Os documentos - leis, projetos de lei, pareceres, justificativas de projetos, votos em separado, pactos, medidas provisórias, etc. - surgiram e ganharam a centralidade da pesquisa, que proporciona os dados para este artigo, na medida em que um primeiro contato com o próprio Estatuto do Nascituro foi feito. Considero que os documentos promovem um diálogo entre si, que além de constituírem a própria etnografia de arquivos, ou desses documentos, garantem legitimidade e coerência contextual para a etnografia, "os documentos devem também ser avaliados como partes de um conjunto - um "dossiê" de documentos, e não apenas como peças únicas de evidência" (CASTRO, 2008, p. 55). . Para compreender o Estatuto do Nascituro era preciso compreender as leis sobre aborto e novas tecnologias reprodutivas - seria possível proibir aborto de gravidez resultante de estupro, ou então proibir pesquisa e descarte com embriōes in vitro? Como estariam estes regulados atualmente? Ou então, quais as diferentes propostas de lei para estes casos? Como elas se faziam possíveis? Quais os documentos e leis citados?

Cada questáo abria um novo leque de documentos, e cada documento abria novas questôes. Os documentos citados podiam ser os mesmos, com a mesma leitura ou interpretação, ou com interpretaçôes diferentes. Os documentos podiam usar de justificativas parecidas, citar justificativas próximas, ou omitir a existência de argumentaçôes contrárias. A primeira grande questão é que todos eles deveriam seguir os princípios básicos da Constituição Federal, e quando não seguissem alguns documentos os ressaltariam. Portanto, todos eles partiam de uma argumentação que deveria ser válida e validada enquanto uma argumentação constitucional, e as diferentes propostas mostraram que seria então possível que embriōes, fetos, zigotos, nascituros, fossem pessoas, ou não fossem nada. Ou então, que fossem pessoas a partir de determinado estágio de desenvolvimento embrionário, ou então em determinadas condições - de vida, expectativa de vida, físicas, sentimentais e morais, etc.

Assim, são os documentos que tornam o nascituro pessoa ou, o que podemos chamar de náo-pessoa. Os documentos constituem um universo de possibilidades a tornar esse espaço do desenvolvimento humano uma pessoa legal. Ainda que possam existir interesses que transbordam esse universo documental, eles expressam uma lógica que deve ser seguida, que abre e fecha possibilidades, que permite diálogos de forma a se produzir pessoas, omitir pessoas, interpretar documentos, e privilegiar determinados assuntos, interpretaçóes, argumentaçôes. Os projetos de lei são construções possíveis nesse universo documental - o Estatuto do Nascituro se apresenta então como uma das possibilidades de interpretaçáo de documentos em vigor; uma possibilidade que opta por tornar o nascituro uma pessoa, e sendo assim, isto é possível.

Mas se é possível tornar o nascituro pessoa ou náo-pessoa, ainda nos paira a dúvida de como os documentos inseridos nesse universo o fazem, ou então, como poderíamos expressar essa arquitetura de construção de argumentações, e para nosso caso e objetivo, construção de pessoas?

\section{Os sujeitos de direito como pessoas}

Parto aqui da ideia das pessoas produzidas nos documentos sobre aborto. Afirmei anteriormente que nos documentos sobre aborto existe uma preocupação com as pessoas, o que significa em defender determinados personagens como pessoas legais, tornando-os assim 
3 I 8 | BRUNA POTECHI

sujeitos de direito de determinada proposição. Sendo os sujeitos de direito, aquilo ou quem, têm seus direitos e deveres prescritos e cujo comportamento se pretende regular (CANTISANO, 2010), eles são as defesas das redações dos projetos de lei apresentados à Câmara dos Deputados sobre aborto, são ainda mais, são sujeitos de direito que têm e devem ter (de acordo com cada redação e argumentação) direitos enquanto pessoas.

Os sujeitos de direito do aborto são mais de um (basicamente três, ainda que possamos visualizar outros de forma indireta $^{8}$ ), são eles: mãe, médico e nascituro. Estes constituem aqueles que aparecem como sujeitos de direito, e suas defesas se complementam da afirmação do ser pessoa destes sujeitos. Ou seja, o eixo de argumentação desses projetos de lei não é o nascituro enquanto uma possível pessoa, mas as diferentes pessoas que podem ser visualizadas nas discussões sobre aborto. A pessoa aparece como eixo pelas defesas de diferentes pessoas que aparecem como sujeitos de direito e que a elas podem ser estabelecidos direitos referentes à Pessoa Física da Constituição Federal. Portanto temos diferentes defesas e objetivos de defesa - pela mãe, pelo nascituro e pelo médico enquanto pessoas.

Quando os projetos de lei têm como defesa a mãe como sujeito de direito, através de seus direitos referentes ao ser pessoa, vimos ser ressaltado o direito em realizar o aborto em casos de gravidez resultante de estupro pela "honra da mulher violada”, pelo sentimento de gestar um filho em consequência de uma violência que é física, moral e psicológica. Os projetos de lei que tentam ampliar as possibilidades de aborto, ou regulamentar a realização de aborto no SUS ressaltam a mulher como sujeito titular de direito, que tem direito sobre o próprio corpo. ${ }^{9}$
O presente projeto de lei tem por objetivo atualizar o Código Penal, adaptando-o aos novos valores e necessidades do mundo atual, particularmente no sentido do reconhecimento dos direitos da mulher enquanto pessoa humana. (Projeto de lei 1135 de 1991, Justificação, de autoria Eduardo Jorge e Sanda Starling)

Em Projeto de Lei sobre a legalização do aborto até os 90 dias gestacionais, o deputado José Genuíno declara:

É interessante observar como a proibição do aborto sempre é acompanhada por toda uma ideologia patriarcal que busca humilhar e desmerecer a mulher enquanto indivíduo participante da sociedade. Além disto, toda a ênfase da vida sexual cai sobre a reprodução que, literalmente, obscurece as outras dimensôes da sexualidade feminina. (Projeto de Lei 176 de 1995, Justificação, de autoria de José Genuíno)

Quando o sujeito de direito defendido é o médico vimos que, como não existe nenhuma lei que assegure que abortos nos casos de gravidez resultante de estupro sejam realizados, o Código de Ética Médica do Conselho Federal de Medicina defende a opção do médico em não realizar o procedimento, podendo recusar seguindo os "ditames de sua consciência”. Assim, mesmo que a mulher possa optar pelo abortamento, não existe como obrigar um médico a lhe garantir o procedimento. Para o Conselho Federal de Medicina, expresso em seu Código de Ética, é o médico o protagonista de sua redação; cabendo a defesa da moral do médico enquanto sujeito de direito, e atribuindo ao Estado a defesa da mulher enquanto tal.

Se nos casos de redaçóes favoráveis à realização de aborto a mulher é personagem protagonista, o médico aparece como coadjuvante. Para 
O Estatuto do NASCituro: QUANDO OS DOCUMENTOS LEGISLATIVOS CONSTROEM PESSOAS $\mid 319$

o Código de Ética Médica o médico é o personagem principal, cabendo a ele realizar ou não o procedimento. ${ }^{10}$ Assim, ao defender os direitos da mulher, pressupóe-se que o aborto deverá ser realizado não considerando os direitos do médico a realizar o abortamento; e ao defender os direitos do médico em recusar abortar um embrião/feto, os direitos de a mulher ter como opção o procedimento são omitidos.

Já o nascituro, torna-se ator principal nas discussões envolvendo os projetos de lei contrários a prática do aborto, ou ainda restringindo as possibilidades de aborto, como no Estatuto do Nascituro. ${ }^{11}$ Em 2007 é apresentado o PL 478/07, de autoria de Luiz Bassuma e Miguel Martini, conhecido como Estatuto do Nascituro que propóe "tornar integral a proteção ao nascituro, sobretudo no que se refere aos direitos de personalidade". Ao classificar em seu art. 2 o nascituro enquanto "ser humano concebido, mas ainda não nascido", a proposta de lei abrange desde embriōes e fetos resultantes de estupro, com má formação fetal, e embriôes produzidos a partir das novas tecnologias reprodutivas mesmo que mantidos fora do corpo humano. Assim, o Projeto de Lei tenta garantir os direitos àquele classificado enquanto "futura pessoa em desenvolvimento".

O presente Estatuto pretende tornar integral a proteção ao nascituro, sobretudo no que se refere aos direitos de personalidade. Realça-se, assim, o direito à vida, à saúde, à honra, à integridade física, à alimentação, à convivência familiar, e proíbe-se qualquer forma de discriminação que venha a privá-lo de algum direito em razão do sexo, da idade, da etnia, da aparência, da origem, da deficiência física ou mental, da expectativa de sobrevida ou de delitos cometidos por seus genitores. (Projeto de Lei 478 de 2007, Justificação, de autoria de Luiz Bassuma e Miguel Martini)
O Estatuto do Nascituro torna o nascituro seu ator principal, constituindo este um ser humano, sujeito de direito e futura pessoa em desenvolvimento. Na justificação do estatuto, os deputados recuperam exemplos dos Estados Unidos e Itália, onde o primeiro garantiu ao nascituro o status de pessoa, e o segundo a condição de cidadão, tentando aproximar tais países da realidade brasileira. $\mathrm{Na}$ justificação a tentativa de personificação do nascituro é mais clara e direta do que no Estatuto em si (futura pessoa em desenvolvimento), sendo que nesse o nascituro é tratado como 'criança por nascer' ou 'bebê'. Um exemplo seria quando os deputados citam um trecho de um artigo da promotora de justiça do Tribunal do Júri do Distrito Federal, Dra. Maria José Miranda Pereira, o qual transcrevo em partes:

Os métodos empregados usualmente em um aborto não podem ser comentados durante uma refeição. O bebe é esquartejado (aborto por curetagem), aspirado em pedacinhos (aborto por sucção), envenenado por uma solução que lhe corrói a pele (aborto por envenenamento salino) ou simplesmente retirado vivo e deixado morrer à míngua (aborto por cesariana). Alguns demoram muito para morrer, fazendo-se necessário ação direta para acabar de matá-los, se não se quer colocá-los na lata de lixo ainda vivos.

Podemos observar que as leis e demais formas e propostas para regular aborto não se focam somente em um personagem. Quando se defende nascituro, a mulher e médico não aparecem como pessoas. $\mathrm{O}$ mesmo se dá quando a mulher é defendida por seus direitos de Pessoa (aqui, Pessoa Física), os direitos do médico e do nascituro como Pessoa não são considerados. Os projetos de lei sobre aborto parecem estar sempre promovendo 
essa construção, onde se aumenta a pessoalidade de um sujeito e se diminui, consequentemente, a de outro.

\section{Quando os documentos omitem as pessoas}

Os documentos sobre novas tecnologias reprodutivas, ao invés de disporem sobre pessoas, tentavam regular as novas formas de reprodução humana, de forma que a família aparecesse com o surgimento dos filhos. Em tais documentos, as pessoas vistas nos documentos sobre aborto não eram mencionadas, mesmo quando pudesse existir uma comparação de determinados processos. $\mathrm{O}$ distanciamento observado entre os documentos sobre um e outro tema evitava uma possível comparação e que as argumentaçóes de um tema fossem utilizadas por documentos que dispunham sobre o outro.

Assim, observamos como os documentos tentavam regular a redução embrionária. A redução embrionária é um procedimento a fim de reduzir a quantidade de embriôes do útero de uma mulher com gestação múltipla. Esta consiste em gravidez de múltiplos embriôes, inseridos artificialmente e simultaneamente, a qual pode acarretar problemas para o desenvolvimento dos embrióes, e para a mulher que os gesta. Dessa maneira, os projetos de lei tentavam regular a quantidade de embrióes inseridos no útero, tentando assim evitar a redução embrionária.

$\mathrm{O}$ projeto segue a mesma preocupação mundial em reduzir o número de gestações múltiplas, o que é compatível com a limitação da transferência de embriôes. A limitação a três transferências evitaria as gestaçôes múltiplas e extinguiria o risco da temida redução embrionária. Temida, pois a redução embrionária significa verdadeiro aborto, com a interrupção do desenvolvimento de um ou mais embrióes já implantados no útero materno. (Projeto de Lei 1135 de 2003, Justificativa, de autoria Dr. Pinotti)

Ainda que exista a preocupação em evitá-la, ela não é proibida. Julgo que isto se dê por dois motivos. O primeiro, e mais óbvio, é que a permissibilidade da redução embrionária é um meio para que os filhos possam existir e, assim, constituir família. Esta, ocupando o lugar dos sujeitos de direitos vistos nos projetos de lei sobre aborto. Já o segundo motivo seria pela própria opção do termo redução embrionária. O termo aparece como um procedimento que é necessário em alguns casos. Diferente do termo aborto, quando aparece em projetos de lei favoráveis ou não. Mesmo nos favoráveis ao aborto, este não é visto como um procedimento cirúrgico, mas um ato, e atitude - em geral da mulher. Mesmo o Estatuto do Nascituro que, proíbe descarte de pesquisa de embrióes in vitro, aborto de fetos portadores de doenças incuráveis, ou aborto de gravidez resultante de estupro, não proíbe a redução embrionária, nem sequer faz menção a ela. Redução embrionária seria assim, um eufemismo de aborto. $\mathrm{O}$ termo viabiliza este tipo de aborto e, portanto, viabiliza a família. Ele ainda coloca esses embrióes a serem eliminados (note que já estando em gestação) em condição de não-pessoa, ou de ser menos pessoa que outros embriôes (inclusive aqueles in vitro, fora do corpo materno).

Algo parecido ocorre com o termo pré-embriâo. ${ }^{12}$ Notei a presença do termo analisando a Resolução do Conselho Federal de Medicina (CFM) 1358/1992 revogada pela Resolução do CFM 1957 de 2010 (ambas tratando sobre normas éticas para a utilização das técnicas de reprodução assistida). Entre as mudanças ocorridas temos a substituição do termo pré-embrião na Resolução anterior para o termo embrião na Re- 
O Estatuto do NASCituro: QUANDO OS DOCUMENTOS LEGISLATIVOS CONSTROEM PESSOAS 32 I

solução atualizada. $\mathrm{Na}$ Resolução atual o termo pré-embriáo praticamente desaparece. No item 6 dos Princípios Gerais temos que a expressão "o número ideal de oócitos e pré-embriōes a serem transferidos para a receptora (...)" é substituída por "o número máximo de oócitos e embriôes a serem transferidos para a receptora (...)." Outro exemplo é a parte intitulada "Diagnóstico e Tratamento de Pré-Embriōes”, a qual é modificada para "Diagnóstico e Tratamento de Embrióes." Nessa parte o item 3 diz: "O tempo máximo de desenvolvimento de pré-embriôes 'in vitro’ será de 14 dias", já na Resolução atual a frase fica: "O tempo máximo de desenvolvimento de embriôes ‘in vitro’ será de 14 dias." A exceção é o caso da criopreservação, enquanto na Resolução de 1992 o termo evitado é embriáo.

No caso da criopreservação, este embriāo - ou pré-embrião, ou nascituro - não nascerá necessariamente. A partir do momento em que é criopreservado ele pode ser utilizado para pesquisa, ou descartado. Assim, ele é tido como menos pessoa que o embriáo ainda não criopreservado. Salem (1997) coloca que no contexto da produção de embriōes extra-corporais, o termo pré-embriâo surge como uma forma de "aplacar resistências às pesquisas com embriôes, e o dilema moral concernente é, nesse contexto, reduzido a um mero problema semântico."13

O termo pré-embrião, assim, possibilita que haja criopreservação, possibilita que haja descarte, possibilita porque pré-embrião o torna menos pessoa, ou não-pessoa. Assim como redução embrionária possibilita que um outro tipo de aborto possa ocorrer. Estes embrióes também se tornam menos pessoa. $\mathrm{O}$ contrário se dá com o termo nascituro - este sim aparece como o ápice da pessoa desse momento de desenvolvimento humano anterior ao nascimento, que poderíamos chamar de embrião, pré-embriāo, nascituro, zigoto, etc.

\section{Consideraçóes finais}

Vejamos o que esta breve exposição pode nos proporcionar para pensar essas construçóes de pessoas. Nessas diferentes defesas, dos diferentes sujeitos de direitos como pessoas, vimos que ao invés de se defender o nascituro como uma pessoa ou como uma não-pessoa, esse discurso só existia por um lado - quando ele era a pessoa defendida. Quando ele era uma náo-pessoa, era nos casos em que ele náo era o sujeito de direito, e dessa maneira nem aparecia na redaçáo do projeto de lei, nos documentos citados, talvez apenas quando um parecer ou voto em separado fossem contrários ao que estava tentando ser proposto - e aí havia um desvio de sujeito de direito, de direitos referentes às diferentes pessoas legais. Não existia assim, uma defesa pelos direitos da mulher enquanto pessoa, por o nascituro ser uma náo-pessoa, ou do nascituro como pessoa, pela mulher ser uma não-pessoa. O que existiam eram sempre afirmações de direitos enquanto pessoa, e sendo assim era possível que mãe, nascituro e médico fossem defendidos por tais direitos.

Entretanto, tais direitos se mostraram ser dependentes, de forma que ao afirmar direitos de Pessoa de alguns dos sujeitos, outros sujeitos pudessem ser automaticamente anulados enquanto pessoa legal, ou melhor, ter seus direitos omitidos da redação. Isto porque a afirmação de um direito dependia que outro fosse anulado: defender a mãe dispor sobre seu corpo é anular o nascituro como pessoa; defender o direito a integridade física do nascituro é anular direitos de pessoa da máe. Os documentos, assim, evitam aproximar esses diferentes sujeitos, mas defender um é anular o outro através da omissão. Seus direitos acabam sendo então dependentes e inversamente proporcionais, de forma que atribuir a condição de ser pessoa a um é omitir a pessoalidade do outro, ou diminuí-la. 
Mais ainda, essas omissōes do nascituro, da mãe, do aborto, das novas tecnologias reprodutivas se mostraram serem formas de dar viabilidade àquilo que se pretendia defender $\mathrm{e}$ regular - já que essa omissão tentava mascarar uma dependência ou anulação de outras pessoas e/ou fatores. Assim os projetos de lei sobre novas tecnologias poderiam anular discussôes sobre a pessoalidade do nascituro, da mãe, do médico e invocar discursos de forma a promover a família - que só apareceria com o surgimento dos filhos. A família, nestes documentos, ocupa o lugar central; como o lugar ocupado pelos direitos enquanto pessoas dados à nascituro, mãe e médico nos documentos sobre aborto. Nesses documentos, temos como exemplo de afastamento quando evita-se aproximar a redução embrionária de aborto, o que não poderia existir em discursos onde o nascituro é pessoa, por exemplo.

Além de mostrar possibilidades de pessoa e não-pessoa; pude observar que as pessoas apareciam nos documentos através das argumentações que poderiam torná-las mais ou menos pessoas, ou mais ou menos pessoas em relação a alguma coisa. Penso essa relação entre ser mais e menos pessoa a partir da afirmação de Fonseca, "assim, se existem pessoas mais merecedoras de direitos, devem existir pessoas menos merecedoras" (FONSECA, 1999, p. 31). ${ }^{14}$ Assim, como o nascituro é "futura pessoa em desenvolvimento" no Estatuto do Nascituro - seu momento ápice de ser pessoa - a mãe volta a ser pessoa, e é mais pessoa que ele, quando esta corre risco de vida.

A primeira hipótese cuida do aborto necessário por ser o único meio de salvar a vida da gestante. Nesse caso, em que dois bens juridicamente tutelados estão no mesmo plano e em conflito, que são as vidas da máe e a do feto, o legislador fez indiscutível opção pela preservação daquela antecedente, permitindo o perecimento da vida do nascituro, mesmo que sem o consentimento da gestante, enquadrando a situação como estado de necessidade, reafirmando a máxima de que nenhum direito é absoluto, nem mesmo o direito à vida. (Relatório Eduardo Cunha PL 1135 de 1991,14 , junho de 2008) $)^{15}$

Ou então, quando a família ocupa lugar de sujeito de direito nos documentos sobre novas tecnologias reprodutivas, fala-se em redução embrionária de gestaçôes múltiplas, nunca em aborto; ele é mais tolerado, mais brando, porque a defesa é pela família. Um embrião já inserido e em desenvolvimento no útero de gestação múltipla é menos pessoa que um embrião in vitro "convencional". Sua eliminação é mais aceita.

Tentei demonstrar, ao longo do texto, como são possíveis essas diferentes argumentações e construçóes legislativas para um mesmo caso. Permissôes de aborto e criminalização, pesquisa e descarte de embriôes in vitro e sua proibição ou mesmo doação, ${ }^{16}$ proibição de aborto e permissão de redução embrionária. E ainda, como estas questóes permeavam a construção das pessoas. Ressaltei algumas formas de os documentos tornarem aqueles que propunham defender (os sujeitos de direito de cada redação) como pessoas legais. Essa constante construção de pessoa se mostrou ser um espaço aberto de se afirmar ou negar uma pessoa. Assim, alguns termos são preferíveis a outros, como nascituro quando este é pessoa, e pré-embrião quando não o é. Vimos então, que os documentos legislativos constituem um amplo espaço de afirmação e negação de pessoas, e ainda mais, que este espaço pode tornar essas diferentes pessoas, mais pessoas em relação umas às outras, de forma que o sujeito de direito defendido é sempre o protagonista de seu documento. Cada personagem tido como sujeito de direito é a maior pessoa, expressa em seu ápice, ainda que, e talvez somente, na redação do documento que o defenda enquanto tal. 


\section{Notas}

1. Este artigo resulta da apresentação no III ENADIR, GT 3: Antropologia, Gênero, Direitos Sexuais e Reprodutivos. Os dados e reflexôes partem da pesquisa desenvolvida no mestrado, onde fui bolsista CNPq. Algumas reflexões apresentadas fazem parte da pesquisa de doutorado, desenvolvida atualmente, que conta com bolsa FAPESP.

2. Após ser apresentado em 2007 à Câmara dos Deputados, ele tramita na Comissão de Seguridade Social e Família onde obtém aprovação em 2010. Atualmente o mesmo PL, após receber parecer positivo da Comissão de Finanças e Tributação em 2013, fora encaminhado para a Comissão de Constituição e Justiça e Cidadania.

3. Mauss, ao inaugurar o conceito como uma condição universal do espírito humano envolvida pelo dado social, apresentaria uma nova linha para se pensar a consciência de si - enquanto pessoa moral. A partir daí muitos autores se debruçam sobre uma leitura da categoria (do espírito humano) proposta por Mauss. Alguns o viram como evolucionista, outros como relativista, outros como neo-Kantiano, outros o viram pela sociedade e dualidade durkheimiana (Ver Allen (1985) e Goldman (1996))

4. Uma das leituras de Mauss desembocou na noção de pessoa ocidental apontada por Dumont - o indivíduo. Dumont (1985) apresenta a construção da pessoa ocidental pautada na ideia de igualdade, gerando uma forma específica de pessoa, pensada enquanto indivíduo.

5. Não estou falando de uma consciência de si, ou de Pessoal Moral.

6. Sobre aborto e novas tecnologias reprodutivas ver Porto (2008), Rohden (2003), Machado (2008), Machado (2013), Luna (2007), Collard e Kashmeri (2011), Chazan (2003), Castro (2009).

7. Não afirmo aqui que documentos, bibliotecas, coleções ou instituiçóes (sozinhos) falam por si só (ver Latour, 2010). Entretanto, pretendo mostrar como um conceito (de pessoa) é formulado dentro disto, e por isto, que podemos chamar de acervo.

8. Como o Estado, família.

9. Existem projetos de lei: propondo permitir aborto em caso de feto portador de anencefalia e/ou enfermidades incuráveis; propondo descriminalizar aborto; propondo legalizar aborto até os 90 dias gestacionais; propondo autorizar aborto em caso de gravidez resultante de estupro por parente.
10. Enquanto a mulher ou a paciente deve ter seus direitos defendidos pelo Estado, não cabendo a este impor uma tarefa que possa infringir a moral dos sujeitos de direito defendido pelo Código de Ética Médica.

11. Muitos tramitam conjuntamente com o Estatuto do Nascituro (PL 478 de 2007).

12. No Projeto de Lei 1135 de 2003, de autoria do Dr. Pinotti, considera-se que pré-embriōes são "o resultado da união in vitro de gametas, previamente à sua implantaçấo no organismo receptor, qualquer que seja o estágio de seu desenvolvimento”. Poderíamos expandir o conceito através de leituras de Embriologia, mas não julgo isso essencial para desenvolver a argumentação.

13. Ao fazer a análise de modo geral sobre como o embrião extra-corporal era concebido enquanto Pessoa, a autora ressalta a afirmação de aspectos biológicos e morais. Do mesmo modo outros autores (Luna, 2009; Strathern, 1992; Chazan, 2008), discutem a autonomia do feto em relação ao corpo da mãe. Notemos mais uma vez que o feto, ou o embrião cheio de relaçôes, são pessoas nascidas em potencial; portanto são pessoas e possuem certa autonomia em relação à mãe; ao corpo da mãe.

14. No caso, a afirmação é feita pensando em "mais humanos" e "menos humanos" para categorias defendidas pelos Direitos Humanos.

15. Declaração do deputado Eduardo Cunha, cujas falas são em favor do nascituro.

16. Sugestão observada no PL 4664/2001, que proíbe o descarte de embriōes fertilizados in vitro, determina a responsabilidade sobre os mesmos e dá outras providências.

\section{Referências bibliográficas}

ALLEN, N. J. The category of the person: a reading of Mauss' last essay. In: CARRITHERS, M.,

BEVILAQUA, Ciméa. Sobre a fabricação contextual de pessoas e coisas: as técnicas jurídicas e o estatuto do ser humano após a morte. In: Mana (UFRJ. Impresso), v. 16, p. 7-29, 2010.

CANTISANO, Pedro J. Quem é o sujeito de direito? A construção científica de um conceito jurídico. Direito. In: Estado e Sociedade, n.37, p. 132 a 151. jul/dez 2010. CHAZAN, Lilian Krakowski. O corpo transparente e o pa- 
324 | Bruna Potechi

nóptico expandido: consideraçóes sobre as tecnologias de imagem nas reconfiguraçóes da pessoa contemporânea. In: Physis vol.13 no.1 Rio de Janeiro Jan./Jun. 2003.

CASTRO, Celso; CUNHA, Olívia M. G. da. Quando o campo é arquivo. In: Estudos Históricos. Rio de Janeiro, n 36, p. 3-5, jul./dez. 2005.

CASTRO, Celso. Pesquisando em Arquivos. Rio de Janeiro: Jorge Zahar, 2008.

CASTRO, Rosana. Construindo corpo, atribuindo direitos: o embriáo como sujeito de direitos no debate legislativo sobre aborto. In: Série Anis. Ano IX, n. 70, outubro de 2009. Disponível em: <http://www.anis. org.br/serie/visualizar_serie.cfm?IdSerie=92> Acesso em 20 de Agosto, 2013.

COLLARD, Chantal; KASHMERI, Shireen. Embryo adoption: Emergent forms of siblingship among Snowflakes families. American Ethnologist, Vol. 38, No. 2, pp. 307-322, 2011.

COLLINS, S. \& LUKES, S. The category of person:anthropology, philosophy, history. Cambridge: Cambridge University Press, 1985.

DUARTE, Luiz Fernando Dias. Indivíduo e pessoa na experiência da saúde e da doença. In: Ciênc. saúde coletiva, 2003, vol.8, no.1, p.173-183.

DUMONT, Louis. O Individualismo: uma perspectiva antropológica da ideologia moderna. Tradução de Alvaro Cabral. Rio de Janeiro: Rocco, 1985.

FERREIRA, Letícia Carvalho de Mesquita. Dos autos da cova rasa: a identificação de corpos não-identificados no Instituto Médico-Legal do Rio de Janeiro, 1942-1960, Rio de Janeiro, FINEP/E-papers, 2009, 198pp.

FONSECA, Claudia. Direitos dos mais e menos humanos. In: Horizontes Antropológicos 10: 83-122, 1999.

"As novas tecnologias legais na produção da vida familiar". In: CIVITAS - Revista de Ciências Sociais, v. 11 (1), Janeiro./Abril., 2011, p. 8-23.

GOLDMAN, Marcio. Uma categoria do pensamento antropológico: a noção de pessoa. In: Revista de Antropologia, São Paulo: USP, vol 39, n. 1, p. 88-109, 1996.

LATOUR, Bruno. The Making of Law. An ethnography of the conseil d'état. Cambridge: Polity Press, 2010.
LUNA, Naara. Fetos anencefálicos e embriōes para pesquisa: sujeitos de direitos. In: Rev. Estud. Fem., vol.17, no.2, Florianópolis, 2009.

Provetas e Clones: Uma antropologia das novas tecnologias reprodutivas. Rio de Janeiro: Editora Fiocruz: 2007.

MACHADO, Igor. O inverso do Embrião: reflexões sobre a substancialidade da pessoa em bebês prematuros. In: Mana (UFRJ. Impresso), v. 19, p. 99-122, 2013.

MACHADO, Lia Zanotta. Gênero: Um Novo Paradigma. In: Cadernos Pagu, São Paulo, p. 107-125, 1998.

MACHADO, Lia; HEILBORN, Maria; GROSSI, Miriam. Antropologia e direitos humanos 4. Blumenau: Novas Letra, 2006.

. Os novos contextos e os novos termos do debate contemporâneo sobre o aborto. Entre as questóes de gênero e os efeitos das narrativas biológicas, jurídicas e religiosas. Série Antropologia, Brasília, v. 419, p. 1-32, 2008.

MAUSS, Marcel. Uma categoria do espírito humano: a noção de pessoa, a de "eu". In: Sociologia e Antropologia. São Paulo. Cosac Naify, 2003.

. As técnicas do corpo. In: Sociologia e Antropologia. São Paulo. Cosac Naify, 2003.

PINHO, Rui Rebelo. Instituiçôes de Direito Público e Privado: introdução ao estudo de direito, noções de ética profissional. São Paulo: Atlas, 1981.

PORTO, Roseli Maria. Objeção de Consciência, Aborto e Religiosidade: Práticas e Comportamentos dos Profissionais de Saúde em Lisboa. Revista Estudos Feministas,Florianópolis, v. 16, p. 661-666, 2008.

POTECHI, Bruna. Quando começa a pessoa legal? O nascituro no legislativo brasileiro. Dissertação de Mestrado. Programa de Pós-Graduação em Antropologia Social. PPGAS-UFSCar. São Carlos. 2013.

RILES, Annelise. Documents: Artifacts of Modern Knowledge. University of Michigan Press, 2006.

ROHDEN, Fabíola. A arte de enganar a natureza: contracepção, aborto e infanticídio no início do século XX. Rio de Janeiro : Editora FIOCRUZ, 2003.

SALEM, Tania. As novas tecnologias reprodutivas: o estatuto do embriẫo e a noção de pessoa. In: Mana, vol. 3, n.1, Rio de Janeiro./Abril., 1997.

STRATHERN, Marilyn. O gênero da dádiva: problemas 
O Estatuto do NASCituro: QUANDO OS DOCUMENTOS LEGISLATIVOS CONSTROEM PESSOAS $\mid 325$

com as mulheres e problemas com a sociedade na Melanésia. Campinas: Editora da UNICAMP, 2006.

Kinship, Law and the Unexpected: Relatives Are Always a Surprise. Cambridge University Press, 2005.

. After Nature: english kinship in the late twentieth century. Cambridge: Cambridge University Press, 1995.

VELHO, Gilberto. Individualismo e cultura: notas para uma antropologia da sociedade contemporânea. Rio de
Janeiro: Zahar. 1981.

VIANNA, Adriana de R. Direitos, moralidades e desigualdades: consideraçóes a partir de processos de guarda de crianças. In: Antropologia e Direitos Humanos 3. Niterói: Editora da UFF, 2005. P. 13-67.

VIVEIROS DE CASTRO, Eduardo. A Fabricação do corpo na sociedade xinguana. In: Boletim do Museu Nacional. 1979.

\section{autora Bruna Potechi \\ Doutoranda em Antropologia Social / UFSCar}

Recebido em 25/11/2013

Aceito para publicação em 16/12/2013 